Article

\title{
Development and Experimentation of a New Mathematical Model for Teaching-Learning the Radioactive Decay Law
}

\author{
Adnane Mamane *(D) and Nadia Benjelloun \\ LIRDIST, Interdisciplinary Laboratory of Research in Didactics of Sciences and Technology, Faculty of Sciences \\ Dhar Mahraz, Sidi Mohammed Ben Abdellah University, B.P. 1796, Fès-Atlas 30003, Morocco; \\ Benjelloun.nadia@yahoo.fr \\ * Correspondence: adnane.mamane@usmba.ac.ma; Tel.: +212-664-606-850
}

Received: 10 May 2019; Accepted: 25 May 2019; Published: 2 June 2019

check for updates

\begin{abstract}
Our plan is to bring professors and their Moroccan pupils to focus on the teaching-learning of physics, without adopting forced mathematical modeling in previously unknown frames and registers, as is actually the practice. The preliminary study consists of developing a new analytical model for the teaching-learning of the radioactive decay law. However, the validation study was conducted to test its pertinence. The results show that, compared to the official model, pupils are very satisfied. In fact, the proposed new model intelligibility frame facilitates the linking of the concept of space of reality, with those of registers and frames. The pupils' performance amounted to $65.33 \%$ in the development of the analytical model of the radioactive decay law, while in terms of suitable applications, pupil performance ranged from $0 \%$ to $75 \%$. This result is partly due to the collaborative work, which induced a very significant increase in pupil performance. They were observed between increases ranging from $33.3 \%$ to $69.5 \%$. In fact, we attribute these good performances to the ICT resources' mobilization, specifically SimulP200, the one that we have exclusively elaborated. These resources have also mitigated the difficulties of the experiment, and those related to the processes of elaboration of different radioactive decay law model.
\end{abstract}

Keywords: teaching-learning physic; ICT; collaborative work; mathematical modeling; registers; frames; space of reality

\section{Introduction}

Physics is singular in its successful mobilization of mathematics. Indeed, in physics, mathematics appears as the inseparable and insubordinate component in the elaboration of contents in their most expressive forms - symbols, formulae, geometric forms, and graphs-historically of mathematical foundations [1-3]. However, it has taken a long way to reach this fact that is currently established. Questions and answers about the links between physics and mathematics have always been a topic of debate. From this comes claims of the kind: Mathematics plays the function of tools in physics for Langevin [4], and for Galilée and Descartes [1]; mathematics is a language of physics for Galilée, Heisenberg, and Poincaré [1]; in this same context, Gaston Bachelard considered mathematics as a current of thought in physics [5]; while Hopwood, Einstein, and Bachelard make their links to the status of the constitution relation [1].

On the side of classroom practices, to make learners aware of the conditions for building scientific knowledge, several authors (Mayrargue et al. [6], Rosmorduc [5], MARTINAND [7]) require integration of history and the epistemology of science alongside their didactics. In this way, they call to mind the consistency of the interdisciplinary aspect and its transcendence in the representations of contents. 
Indeed, Duval [8] makes the point that the integrative understanding of a conceptual content is based on the coordination of at least two representation registers. Again, the incessant need for the distinction between the objects of reality and the objects of the physicist inspired Malafosse et al. [9] in the creation of the concept of reality space.

Moreover, the connected class of the third millennium requires the spontaneous use of its new natural tools of survival, which are the ICT. While, according to the recent study by Mastafi [10], there are only $11 \%$ among Moroccan primary and secondary school teachers who often use ICT in the classroom, $13 \%$ use them occasionally, and the majority of teachers $(61 \%)$ of the sample never used it. The typology of their uses in class covers: Power Point (60\%), educational software (39\%), internet research $(34 \%)$, simulation software $(25 \%)$, and $54 \%$ for other educational activities ExAO: experience assisted by ordinator), serious games, interactive digital tables). According to the study conducted by Mamane et al. [11], on the preferences of Moroccan pupils concerning the use of ICT in physics, these pupils look for exercises or first consult those who are solved. Towards almost equal preference are the use of ICT in the documentation, research of photos of experiments, or their schemes; viewing simulations of experiments or researching their videos. The same study established that relative to websites, the spectrum of pupil preferences is as follows: Pupils would search $75.2 \%$ via Youtube, $40.9 \%$ via Facebook, $41.6 \%$ via websites of Moroccan high schools, $56.9 \%$ through forums, and $64.2 \%$ via other safe and reliable websites. Or again, the ACP operated on three elements that can serve the didactics of physical sciences, namely the use of ICT, experimentation, and mathematical modeling. It follows that $86.9 \%$ of pupils prefer mathematical modeling ready phenomena in the physical sciences, which build them, as long as they are resources mobilized by ICT.

\section{Problematic}

In 2015, the Moroccan Ministry of National Education [12] issued a damning report (among others). It denounces the low level observed in almost all pupils in languages, mathematics. and scientific disciplines. This report, taken as an indicator, calls on all those involved in the promotion of the national education, through their teaching skills, educationalists, politicians, administrations, families, and societal organizations, to reflect on their current choices.

More precisely, in a previous work, Mamane et al. [13] noted the existence of a great lack of institutional structures of interdisciplinarity between all disciplines, as well as between mathematics and physics. As a result, the classroom practices of teachers of these two disciplines are expressed in terms of intuitive initiatives, without any professional reference at the national level or scientific basis.

Hence, we are interested in the case of teaching and learning the phenomenon of radioactive decay, in the second year of the Moroccan baccalaureate of scientific branches LES (life and earth sciences) or PC (physics and chemistry). It turns out that in the literature, the activities of modeling have been based on some analogies made between this phenomenon and other facts related to contents that they frequently used: The roll of dice [14-16] or coins [17], the random draws of beans or balls of two different colors contained in an urn [18], and the construction graph of radioactive decay using paper bars and glue [19]. Moreover, the assembly of experiments in class requires apparatus, radioactive materials, and adequate security devices of handling and storage, hitherto nonexistent in high schools in Morocco. In addition, these same authors agree that the use of radioactive materials in the classroom is not always practical or desirable, with the exception of Lapp [20], who proposed that during this course, examples of naturally radioactive elements can be presented, provided you have at least one Geiger-Muller counter.

Moreover, for these two classes of the Moroccan baccalaureate, this lesson involves the notions of logarithm and exponential functions, linear differential equations of the first order, and calculation of probabilities [21]. This is done at a time when, by far, these notions have not yet been conducted in the mathematics class [22]. Whereas, they are at the heart of almost all the lessons of physics. This discarded all reprogramming for mathematics lessons, because they are in a pedagogical logic and didactic specific to it. They place the teaching of these notions among the lessons of the second 
semester. Knowing that, according to the work of Hughes et al. [19], in many cases, pupils are not used to manipulating the exponential functions of mathematics and lack the necessary tools to understand and interpret equations in which they appear.

\section{Research Paradigm}

\subsection{Theoretical Reference Concepts}

It is at the heart of our theoretical approach that the concepts of semiotic and semantic register, space of reality, framework of rationality, and frame of intelligibility are placed [23]. Indeed, it is thanks to their epistemological statuses in their original contexts that we owe our inspiration to integrate them. In doing so, we mobilize them particularly, as reference concepts of the paradigm of this work, just as they pact among its didactic engineering, in the sense of Artigue [24].

Indeed, the reputed quote of Albert Camus: "Misnaming things is adding to the misfortune of the world", refers to the idea of the coordination of semiotic registers invoked in the work by Duval [8], in which he criticized the generally accepted idea that the relevant choice of a single semiotic register allowed the understanding of the conceptual content represented. We quote here, this jewel of the author: "The (integrative) understanding of a conceptual content is based on the coordination of at least two registers of representation, and this coordination is manifested by the speed and spontaneity of the activity conversion. [...] In fact, such coordination is far from natural. And it does not seem to be possible in the context of a teaching mainly determined by conceptual content" [8]. Particularly, Duval [25] asserts that it is only by means of semiotic representations that an activity on mathematical objects is possible, since mathematical objects, by the fact that they are abstract, are not directly accessible to perception, nor are they in an immediate intuitive experience, as the so-called "real" or "physical" objects are. It is in this perspective that Malafosse et al. [9] created and defined the notion of reality space by: "The space of reality is therefore the set of real objects and events outside of thought of the subject, and on which carry the mental activity of conceptualization. [...] we can consider that the acquisition of concepts in physics is done by collecting information in the reality space (objects and experimental situations created or not) and requires their processing in various rationality frame. The notion of space of reality is therefore fundamentally different from the notion of frame in that the space of reality is external to the subject while the frame is an internal space of thought".

Moreover, for the notion of rationality frame, Malafosse et al. [26] set the following definition: "a frame of rationality is a coherent whole of the functioning of the thought characterized essentially by its world of objects and its rules of reasoning and validation. It is within this structure that semiotic and situational information takes on a dialectical meaning". Taking into account the duality familiar/scientific frame initiated by Vygosky, these authors segment the frame of rationality into three tributaries: Cultural frame (mathematics or physical sciences), didactic frame built for the purpose of transposition knowledge between a scientific community and the pupil in a learning situation, and finally, the personal personalities of the pupils. Later, in another work, Malafosse [27] describes the context of devolution of knowledge. The author explains the threefold origin of conceptualization; namely, individual conceptions of pupils or teachers, scientific conceptions (acquired through didactic mediation), and familiar conceptions (acquired through social mediation).

Finally, Malonga Mongabio et al. [28], in an example of a study of physics textbooks on the modeling and semiotic registers, introduced the concept of intelligibility frame, for the construction of favorable didactic diagrams of teaching-learning physics. They explicitly delimited the meaning of this concept in the context of the following quote: "One of the aims of physics teaching is to foster the construction of a frame of intelligibility to give pupils access to the type of knowledge that, in the eyes of physicists, makes the world intelligible, i.e., the ability to relate the material world and the world of theories and models. We find this partition in the diagram of Malafosse (Malafosse et al., 2000) whose epistemological position is based on the affirmation of a "space of reality" and whose didactic positioning is characterized by the linking of frame of rationality (Lerouge, 2000) and semiotic register". 
Meanwhile, on the side of the notions of model and modeling, a large part of scholarly activities attaches a great importance to the use of models, their modifications, their validation, their reproduction, and their creations.

Korzybski states that: "A map is not the territory" (1998 Eclat, First Aid Collection: Paris). In the context of this saying, a model is a formal representation of a problem, a process, an idea, or a system. It is never an exact replica, but rather an abstract image that can represent the main aspects of the structure, properties, or behavior. Although it represents a real situation, it differs from this situation. According to Martinand [29], a model allows the apprehension of two important aspects of reality. First, it facilitates the representation of the hidden, by favoring the transition to relational and hypothetical representations. Then, it helps to think the complex. It allows for describing the interaction variables, the internal relations between these variables, and the values of the external constraints by identifying and manipulating the systems.

Modeling proves to be an essential component of human activity since it is present whenever the individual tries to understand, interpret the different phenomena of the world, and make predictions. Man perceives the world by constructing mental models. "Modeling is then the creation of a relation between the projected objects of the reality space and the reference situations. For example, an object such as a copper pipe can be apprehended through various frames of rationality: a pipe in the familiar plumber's frame, an electrical resistance in the context of electricity, a weapon in the familiar frame of a hooligan, etc. Each frame makes it possible to reach a fragmented view of the object which, as such, exceeds all of its projections, and it is possible that new frames allow a previously ignored vision. [...] The specific difficulty of the physicist lies then in the operation of projection of the space of reality on the cultural frame of the physics, the erroneous conceptions of the pupils appearing like a projection of this space of reality in a frame of rationality inadequate" [9].

\subsection{Didactic Engineering}

According to Douady [30], the term didactic engineering designates a set of class sequences conceived, organized, and articulated over time in a coherent way to carry out a learning project. He adds: "the project evolves under the reactions of the pupils and according to the choices and decisions of the master". For Marty [31], the construction of didactic engineering is based on the realization of predefined training sequences, with measurable objectives, sanctioned by an evaluation tool that opens the way to any readjustment. Thus, Douady and Marty agree on the fact that didactic engineering is both a product, a result of an analysis, and a process in which the teacher implements activities by adapting it.

For Artigue [24], the didactic engineering is in the register of case studies whose validation is essentially based on the internal comparative approach, characterized by the notion of a priori analysis. The author presented didactic engineering as both a research methodology and a driver of didactic progression. According to her, the didactic engineering has acquired the qualification of research methodology, thanks to its approach that it implements, in the form of experimental schemes based on didactic achievements in class, i.e., "on the conception, realization, observation and analysis of teaching sequences". She attributed to didactic engineering the qualifier of a motor of didactic progression, from the moment when its methodology was the initiator of reflections on concepts, like "the notions of institutionalization [...], the memory of the class, [...] the problems of transmission and reproducibility".

\section{Methodology}

Our methodology is based on general axes. We quote the formulation of a problem, explaining the originality of this work in relation to literature; the statement of research questions and hypotheses, and the delineation of its theoretical paradigm; the mathematical elaboration of the ModLI; sampling, experimentation, and discussion of results from a preliminary study; and a validation study. 


\subsection{Characteristics of Experiment}

On the basis of this work, the phases of the experiment are divided on a preliminary study, and a validation study, as follows:

The sample of the preliminary study consists of 16 pupils from the LES and PC branches, from two high schools in the city of Meknes. The analysis a priori allowed the design of the teaching-learning sequences of this study, their realization, and their analysis, around the didactic observations, relative to our alternative, we term ModLI (model of linearization per interval). The activities were designed on the basis of an alternation between the individual work of the pupils and the collaborative work in intergroups with rotating members.

The sample of the validation study consists of two classes of the second year of the scientific baccalaureate of branches LES (37 pupils) and PC (38 pupils), from the high school Mohamed Ajana in Meknes city. Each class was taken separately. This study is characterized by the design of the teaching-learning sequences, their realization, and their analysis, for ModLI.

The preliminary study and the validation study were conducted with the mobilization of the ICT resources and in the light of conclusions drawn from two studies that Mamane et al. have achieved before. The first one [11] traced the spectrum of pupils' preferences for ICT resources they would solicit in physics, especially, during the learning of radioactive decay; while the second [23] verified the role of ICT in mitigating the difficulties of teaching and learning the phenomenon of radioactive decay.

\subsection{Research Questions}

The privileged epistemological status of the question is categorical on the fact that it is preceding the hypothesis, on the way of the search for answer(s). Thus, we propose the framework questions as follows:

- What causal relationships exist between the Moroccan curricular orientations, and the blockages observed during the teaching-learning of the phenomenon of radioactive decay?

- Where are the degrees of difficulties related to the teaching and learning of radioactive decay situated, and where are those related to the mobilization of mathematics?

- What solutions are we proposing? On which theoretical and organizational pillars are we based to verify that these solutions are good alternatives?

\subsection{Research Hypotheses}

We follow through the formulation of our working hypotheses:

- We believe that the mobilization of ICT increases greatly the success of teaching and learning of radioactive decay.

- We believe that the mobilization of mathematics, in their frame of intelligibility, facilitates the linking of registers and frames, and considerably attenuates the difficulties of the teaching-learning of radioactive decay.

- We believe that ModLI is an alternative to the blockage observed in the teaching and learning of radioactive decay, under the current Moroccan official instructions.

- We believe that collaborative work greatly attenuates the difficulties of teaching learning of radioactive decay. Even more, in groups with rotating members.

\subsection{ModLI Mathematical Elaboration}

The mathematical formalism behind the development of ModLI is as follows: 
4.4.1. Approximate expression of the population number $\mathrm{N}(\mathrm{t})$

The interval I of the time of the radioactive decay is written as:

$$
\begin{gathered}
\left.\left.\left.\left.\left.\left.\mathrm{I}=\left[0, \infty[=\{0\} \cup] 0, \mathrm{t}_{1 / 2}\right] \cup\right] \mathrm{t}_{1 / 2}, 2 \mathrm{t}_{1 / 2}\right] \cup\right] 2 \mathrm{t}_{1 / 2}, 3 \mathrm{t}_{1 / 2}\right] \cup \ldots \cup\right](\mathrm{n}-1) \mathrm{t}_{1 / 2}, \mathrm{nt}_{1 / 2}\right] \cup \ldots \\
=\mathrm{I}_{1} \cup \mathrm{I}_{2} \cup \ldots \cup \mathrm{I}_{\mathrm{n}} \cup \ldots
\end{gathered}
$$

For all $\left.\left.\mathrm{t} \in \mathrm{I}_{\mathrm{n}}=\right](\mathrm{n}-1) \mathrm{t}_{1 / 2}, \mathrm{nt}_{1 / 2}\right]$, we can approach the number of radioactive populations by affine functions of the form:

$$
\mathrm{N}(\mathrm{t})=\mathrm{a}_{\mathrm{n}} \mathrm{t}+\mathrm{b}_{\mathrm{n}}
$$

$\mathrm{n}$ is a new parameter we introduce, and call it "order of radioactive decay". It is defined by:

$$
\forall \mathrm{t} \in \mathbb{R}, \exists \mathrm{n} \in \mathbb{N} \text { such as } \frac{\mathrm{t}}{\mathrm{t}_{1 / 2}} \leq \mathrm{n}<1+\frac{\mathrm{t}}{\mathrm{t}_{1 / 2}}
$$

The notation $\mathrm{t}_{1 / 2}$ means the radioelement half-life.

Now, by solving the equation system:

$$
\left\{\begin{array}{c}
>\mathrm{N}\left((\mathrm{n}-1) \mathrm{t}_{1 / 2}\right)=\frac{\mathrm{N}_{0}}{2^{\mathrm{n}-1}} \\
\mathrm{~N}\left(\mathrm{nt}_{1 / 2}\right)=\frac{\mathrm{N}_{0}}{2^{\mathrm{n}}}
\end{array}\right.
$$

we find

$$
\left\{\begin{array}{c}
a_{n}=-\frac{N_{0}}{2^{n}} * \frac{1}{t_{1}} \\
b_{n}=(n+1) \frac{N_{0}}{2^{n}}
\end{array}\right.
$$

So, the approximate expression of the number of the radioactive population remaining in the sample at time $t$ can be written as:

$$
\mathrm{N}(\mathrm{t})=\frac{\mathrm{N}_{0}}{2^{\mathrm{n}}}\left[(\mathrm{n}+1)-\frac{\mathrm{t}}{\mathrm{t}_{1 / 2}}\right] \text { wherein } \frac{\mathrm{t}}{\mathrm{t}_{1 / 2}} \leq \mathrm{n}<1+\frac{\mathrm{t}}{\mathrm{t}_{1 / 2}} .
$$

4.4.2. Approximate Expression of the Time in the Interval $I_{n}$

The approximate expression of $t$ drawn from that of $\mathrm{N}(\mathrm{t})$, is of the form:

$$
t=t_{1 / 2}\left[(n+1)-2^{n} \frac{N(t)}{N_{0}}\right] \text { wherein } \frac{\ln \frac{N_{0}}{N(t)}}{\ln 2} \leq n<1+\frac{\ln \frac{N_{0}}{N(t)}}{\ln 2}
$$

where $\mathrm{n}$ is the same parameter that we called "radioactive decay order".

To make it simpler, we define the radioactive populations by:

$$
\mathrm{N}_{0}=2^{\mathrm{y}} \text { and } \mathrm{N}(\mathrm{t})=2^{\mathrm{x}}
$$

with:

$$
\forall \mathrm{x} \text { and } \mathrm{y} \in \mathbb{R}, \mathrm{n} \in \mathbb{N} \text { such as } \mathrm{y}-\mathrm{x} \leq \mathrm{n}<1+\mathrm{y}-\mathrm{x} \text {. }
$$

\section{Preliminary Study}

\subsection{Didactic Observartions}

We imagine that the analysis of the processes of passages from experimental reality to mathematical models is indispensable. That is to say, proceeding to the analysis of the transition processes between radioactive decay in the context of physics and linear algebra (Linear algebra: The branch of mathematics that is interested in vector spaces, linear transformations, and the general formalization of theories of 
linear equations systems.) in the context of mathematics. That is why, on the account of the analysis a priori, we emit the points below, which will be our didactic observations.

- In terms of reality space: Discuss the influence of ICT mobilization on the activity of production and apprehension of different radioactive decay models, knowing that it is impossible to realize real classroom experiments;

- In terms of register: Check the degree of control of the pupils to pass between different registers, by their capacities to look for the numerical regularities and to transpose them in graphic representations, and by their capacities to establish the analytical expression reflecting the radioactive decay law;

- In terms of organization of work: Analyze the influence of the alternation between individual work and collaborative work, on the teaching and learning of mathematical modeling of phenomena in physics.

\subsection{Target Level}

The second year of the scientific baccalaureate of the LES and PC branches is the target level in this work. This is where the teaching-learning of the phenomenon of radioactive decay poses a problem in the mathematical formalism currently adopted.

\subsection{Intervention Modalities}

The preliminary study for ModLI, undertaken with a sample of sixteen pupils, was carried out separately with three groups consisting of four pupils of PC branch (from the high school IBN ROUMI of Meknes), three pupils also of PC branch (from the high school Mohamed AJANA of Meknes), and nine pupils from the LES branch (from the high school Mohamed AJANA of Meknes). These pupils were volunteers with whom the work was programmed according to their free time, in the sites of their high schools that the corresponding administrations put at our disposal.

Our preliminary study was conducted in two stages. We have devoted the first step to recalling the different existing radioactive decay models. The second stage was devoted to the experimentation of the new model: ModLI.

In our methodological approach specific to this work, the experimentation had a piloting according to the didactic engineering from the point view of ARTIGUE [24], during which we were able to raise the didactic observations. The scripting of our interventions were in the form of individual work sequences and collaborative work in intergroups of pupils with rotating members, alternated by the mobilization of ICT [32]. In particular, the mobilization of SimulP200 (Polonium 200 radioactive decay Simulation chessboard), the ICT resource that we developed exclusively to use during this research.

We have ensured that pupils' involvement is systematic and operational in all stages of the development of the ModLI. Thus, we intend to draw important conclusions, based on analyses that we carried out.

\subsection{Experimentation}

\subsubsection{Presentation of Our Created ICT Resource}

SimulP200 is an ICT resource whose acronym is derived from its full name: "Polonium 200 radioactive decay Simulation chessboard" [23]. This ICT resource was developed by our team using the Python language. This language is placed online under a free license (https://www.python.org/psf/) (see the Supplementary). Indeed, after having installed this software on five pupils' laptops, in addition to the teacher's laptop, its interface offers the possibility to create code files; in this case, the code of SimulP200. Once properly written by our team and saved in pupils' laptops, each file becomes ready to use because it has the same distinctive logo and a name it has been given. 
We explained to the pupils that using SimulP200 consists of a simple click on their file previously saved on their laptops, after which its interface appeared. They discovered that it has the shape of a checkerboard of tiles $(40 \times 25)$, all initially oranges. We told them that each orange tile plays the role of a nucleus of ${ }^{200}$ Po not yet disintegrated. But once disintegrated, its color becomes green. The built-in clock in the interface displays time $t$, while another counter displays the number of remaining radioactive nucleus $\mathrm{N}(\mathrm{t})$.

Example of SimilP200 interfaces:

The activity of the pupils during the individual work consists of raising the values from the class display that the teacher activates on SimulP200 as in Figure 1. However, during the collaborative work, each group of pupils manipulates this resource, on one of the five laptops they could bring for this purpose.

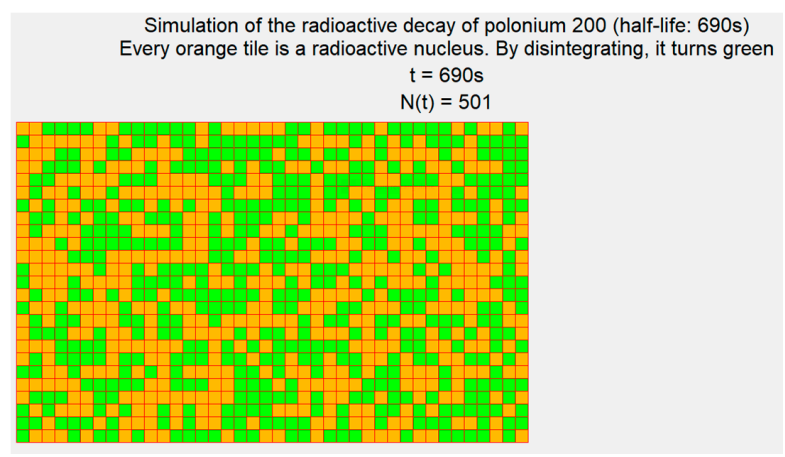

Figure 1. Screenshot of SimulP200 in $\mathrm{t}=\mathrm{t}_{1 / 2}=690 \mathrm{~s}$.

\subsubsection{Test 1}

\section{- Statement}

On the basis of the instructions below, deduce the graphical model of $N(t)$ :

First instruction: Draw an orthonormal coordinate system, whose abscissa are the times $t=n t_{1 / 2}$ with $\mathrm{E} \in \mathrm{N}$, and the coordinates are the corresponding populations that you find through the class display.

Second instruction: In ways that you think are reasonable, propose forms for the graph of $\mathrm{N}(\mathrm{t})$.

- Results

Pupils proposed two graph forms of $\mathrm{N}(\mathrm{t})$, Chart 1a,b, as below:

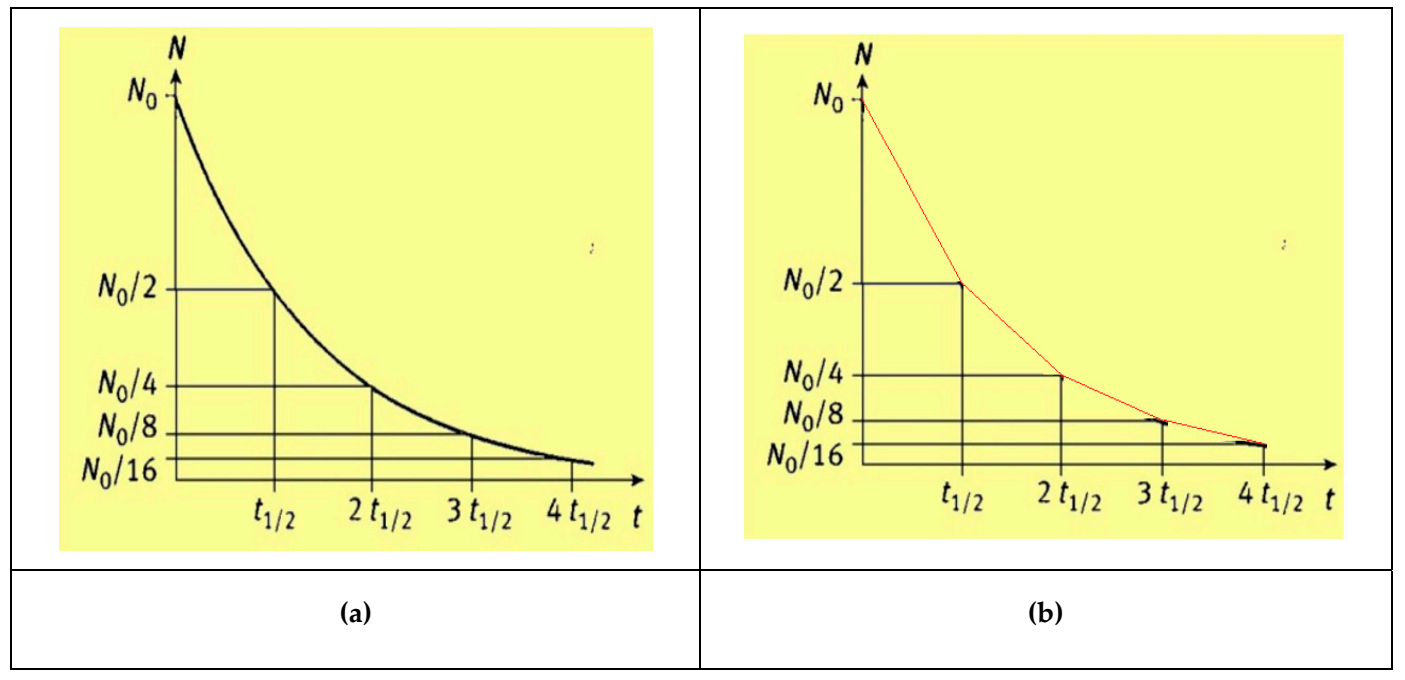

Chart 1. (a): Curve of ModLet ${ }^{\text {, }}(\mathbf{b})$ : Curve of ModLI. 
Pupils' production statistics are in Table 1 below:

Table 1. Test 1 statistic result.

\begin{tabular}{|c|c|c|c|c|c|}
\hline \multirow{2}{*}{ Answers Analysis } & \multirow{2}{*}{ Branch } & \multicolumn{4}{|c|}{ Acceptable Rate Works } \\
\hline & & \multicolumn{2}{|c|}{ in Individual Configuration } & \multicolumn{2}{|c|}{ in Intergroups with Rotating Members } \\
\hline \multirow{2}{*}{ Plots of a landmark } & PC & $100 \%$ & \multirow{2}{*}{$100 \%$} & $100 \%$ & \multirow{2}{*}{$100 \%$} \\
\hline & LES & $100 \%$ & & $100 \%$ & \\
\hline \multirow{2}{*}{$\begin{array}{l}\text { Productions similar to } \\
\text { curve in Chart 1a }\end{array}$} & PC & $85.7 \%$ & \multirow{2}{*}{$75 \%$} & $100 \%$ & \multirow{2}{*}{$95.2 \%$} \\
\hline & LES & $66.7 \%$ & & $91.7 \%$ & \\
\hline \multirow{2}{*}{$\begin{array}{l}\text { Productions similar to } \\
\text { curve in Chart } 1 \mathrm{~b}\end{array}$} & PC & $85.7 \%$ & \multirow{2}{*}{$81.2 \%$} & $100 \%$ & \multirow{2}{*}{$100 \%$} \\
\hline & LES & $77.8 \%$ & & $100 \%$ & \\
\hline
\end{tabular}

- Conclusion

In intergroups with rotating members configuration, pupils confirmed their ability to draw the $\mathrm{N}(\mathrm{t})$ curve (Chart $1 \mathrm{~b}$ ), through a succession of affine functions. This is, indeed, the first premise on the way to the development of ModLI. The pupils of the LES branch follow those of the PC branch, with all forms of work combined; while all pupils have achieved $100 \%$ success in their productions, making calls to contents they use frequently.

\subsubsection{Test 2}

\section{- Statement}

We want to establish the general analytical model of the radioactive population $\mathrm{N}(\mathrm{t})$, and establish that of time t. So, for each of the instructions, we ask you to work individually and then in intergroups with rotating members.

First instruction: Establish the expression of $\mathrm{N}(\mathrm{t})$ relative to Chart 1a.

Second instruction: Establish the expressions of $\mathrm{N}(\mathrm{t})$ relating to the first three time intervals of Chart $1 b$.

Third instruction: Deduce the general analytical model of $\mathrm{N}(\mathrm{t})$ relative to Chart $1 \mathrm{~b}$.

Fourth instruction: Deduce a general form of time intervals relative to Chart $1 \mathrm{~b}$.

Fifth instruction: Establish the general expression of the time relative to Chart $1 \mathrm{~b}$.

- Result

The results of the analysis of the transcriptions are represented in the following grid:

- Conclusion

The analytical model of radioactive decay, as it is officially recommended (we symbolize it by ModLet ${ }^{t}$, is an epistemological obstacle, as opposed to the ModLI we propose. In fact, neither the individual nor the collaborative work between pupils has led to an acceptable and methodical elaboration of an analytical model of $\mathrm{N}(\mathrm{t})$, from the curve of Chart 1a (an unknown mathematical content). Whereas the linking of the curve of Chart $1 \mathrm{~b}$, with the effort of the establishment of the analytical model of $\mathrm{N}(\mathrm{t})$, unlocked the teaching-learning situation, thanks to the mobilization of a content mathematical similar to the usual treatments.

By comparing the statistical analysis grids of Tables 1 and 2, it leads to a very significant improvement in the process of developing analytical models by pupils. In fact, on this basis, the passages between the physical rationality frame and the mathematical rationality frame [26] have operated with much more success, culminating in the development of the ModLI. Again, collaborative work has increased pupil performance from $0 \%$ to $75 \%$ and, finally, $100 \%$, in establishing the general analytic expression of time $t$, while for the establishment of that relating to the number of radioactive population $\mathrm{N}(\mathrm{t})$, it rose from $0 \%$ to $31.2 \%$ and, finally, $95.2 \%$. 
Table 2. Test 2 statistic results.

\begin{tabular}{|c|c|c|c|c|c|}
\hline \multirow{2}{*}{ Answers Analysis } & \multirow{2}{*}{ Branch } & \multicolumn{4}{|c|}{ Acceptable Rate Works } \\
\hline & & \multicolumn{2}{|c|}{ in Individual Configuration } & \multicolumn{2}{|c|}{ in Intergroups with Rotating Members } \\
\hline \multirow{2}{*}{$\begin{array}{l}\text { establishment of the expression of } \mathrm{N}(\mathrm{t}) \\
\text { relative to the curve in Chart } 1 \mathrm{a}\end{array}$} & PC & $0 \%$ & \multirow{2}{*}{$0 \%$} & $0 \%$ & \multirow{2}{*}{$0 \%$} \\
\hline & LES & $0 \%$ & & $0 \%$ & \\
\hline \multirow{2}{*}{$\begin{array}{l}\text { establishment of the first three expressions } \\
\text { of } N(t) \text { relative to the curve in Chart } 1 b\end{array}$} & PC & $57.1 \%$ & \multirow{2}{*}{$37.5 \%$} & $88.9 \%$ & \multirow{2}{*}{$71.4 \%$} \\
\hline & LES & $22.2 \%$ & & $58.3 \%$ & \\
\hline \multirow{2}{*}{$\begin{array}{l}\text { general analytical model deduction for } \mathrm{N}(\mathrm{t}) \\
\text { relative to the curve in Chart } 1 \mathrm{~b}\end{array}$} & PC & $42.9 \%$ & \multirow{2}{*}{$31.2 \%$} & $100 \%$ & \multirow{2}{*}{$95.2 \%$} \\
\hline & LES & $22.2 \%$ & & $91.7 \%$ & \\
\hline \multirow{2}{*}{$\begin{array}{l}\text { deduction of a general form of time } \\
\text { intervals from the curve in Chart } 1 b\end{array}$} & PC & $71.4 \%$ & \multirow{2}{*}{$50 \%$} & $100 \%$ & \multirow{2}{*}{$90.4 \%$} \\
\hline & LES & $33.3 \%$ & & $83.3 \%$ & \\
\hline \multirow{2}{*}{$\begin{array}{l}\text { establishment of a general analytical model } \\
\text { of time } t \text { for the curve in Chart } 1 \mathrm{~b}\end{array}$} & PC & $85.7 \%$ & \multirow{2}{*}{$75 \%$} & $100 \%$ & \multirow{2}{*}{$100 \%$} \\
\hline & LES & $66.7 \%$ & & $100 \%$ & \\
\hline
\end{tabular}

\subsubsection{Conclusions}

In terms of comparison, on the one hand, in the context of the official recommendations, the pupils definitively are blocked once when they reach the mathematical phase of the introduction of the analytical models of the radioactive decay; namely, the differential equations and their solutions, the logarithmic and exponential functions, and the different manipulations that govern them. While in the ModLI teaching-learning situation that we are proposing, the pupils engage in methodically undeniable activities on the path of the process of constructing mathematical models. On the other hand, collaborative work between pupils greatly increases the success of their learning.

Thus, by removing the inherent difficulties of mathematical content and their mastery, teaching-learning in physics of the phenomenon of radioactive decay becomes an opportunity to reinforce the skills of pupils in terms of know-how, during the various stages of the modeling process.

\section{Validation Study}

In view of a routine use of the ModLI in physics classes, we propose to carry out the validation study tests in whole-class situations of the Moroccan baccalaureate LES and PC branches.

\subsection{Intervention Modalities}

With the support of the administration of the High School Mohamed AJANA of Meknes, the field of the validation study was two full classes of the second year of the baccalaureate, from the school year that followed that of our preliminary study. We have chosen these classes so that none of the pupils in the preliminary study working groups are included. The study was conducted with a class of 38 pupils from PC branch, then with another class of 37 pupils from LES branch. In their respective classes of the physical sciences, these pupils had already finished the officially programmed courses, which are related to the themes of this work.

For this, all arrangements were made, and we started this validation study by reviewing the different existing models of the radioactive decay law. It was followed by tests relating to the mathematical modeling of the said law, for a particular case where the time is defined by $t=n t_{1 / 2}$ and where $\mathrm{n}$ is a natural integer. We went on to administer the validation tests on the ModLI account.

To do this, the administration of this high school presented the doctoral researcher to the pupils, informing them that the course of the tests will be filmed with all the required authorizations. The latter introduced the assistant professor during the administration of validation tests. He also clarified the guidelines to be followed and the restrictions that govern the conduct of this stage of scientific research. This scenario took the necessary time to explain the essential role of pupils in the success of this phase of scientific research. The instruction states that pupils must strictly restrict themselves to individual work; and, if necessary, it is allowed for any pupil to converse only in a very low voice, exclusively with one of the two professors responsible for administering the tests. Since then, the work has been 
divided into two steps consisting of 10 sequences. The researcher as a professor of this class took care of the logistic part concerning ICT. The first step (from the first to the fourth sequence) was devoted to an overview of the already existing models of the radioactive decay law. The second step (from the 5th to the 10th sequence) was used for the experimentation of the ModLI experiment by administering its tests.

\subsection{Experimentation Results and Discussion}

It is a process guided by analysis of a prior of pupils' ability to complete the mathematical modeling process and to produce an acceptable analytical model, in a simple case belonging to the usual treatments, then successively, in the case of ModLI.

\subsubsection{Existing Models of the Radioactive Decay Law}

The first step of our validation study focused on the activities of the presentation of existing models of the radioactive decay law, by:

- ModNat, the concept of the Natural Model of radioactivity decay by the figure 2 in [33], figure 3 in [34], and chart 2 in [35] (first sequence).

- ModTab, the concept of Tabular Model of radioactive decay by the chart 3 in [36] (second sequence).

- ModGraph, the concept of Graphical Model of radioactive decay by the chart 4 in [37] (third sequence).

- ModAnalyt, the concept of Analytical Model of radioactive decay (fourth sequence):

As officially recommended [21], we have introduced, in contents provided to pupils, the concept of analytical models of radioactive decay, through different expressions:

The differential equation of the first order of $N(t)$ :

$$
\frac{\mathrm{dN}}{\mathrm{dt}}+\lambda \mathrm{N}(\mathrm{t})=0
$$

The expression of his solution in $\mathrm{N}(\mathrm{t})$ :

$$
\mathrm{N}(\mathrm{t})=\mathrm{N}_{0} \mathrm{e}^{-\lambda \mathrm{t}} \quad \text { with } \quad \lambda=\frac{\ln 2}{\mathrm{t}_{1 / 2}}
$$

The expression of the time $t=f(N(t))$ :

$$
\mathrm{t}=\frac{1}{\lambda} \ln \frac{\mathrm{N}_{0}}{\mathrm{~N}(\mathrm{t})}
$$

\subsubsection{Test 3 (Part 1)}

From the perspective of analysis a priori, the tests are the means to note important didactic observations on the following points:

In terms of intelligibility frame: The influence of the absence of interdisciplinary elements between mathematics and physics, on the activity of apprehension and mathematical modeling on radioactive decay;

In terms of registers: The influence of the different passages between registers on the search for numerical regularities and their transposition into equations reflecting the radioactive decay law.

- Statement

Using the information in Chart 2, shown opposite, deduce the values of $N(t)$ for times $t=4 t_{1 / 2}$ and $t=5 t_{1 / 2}$. (fifth sequence). 


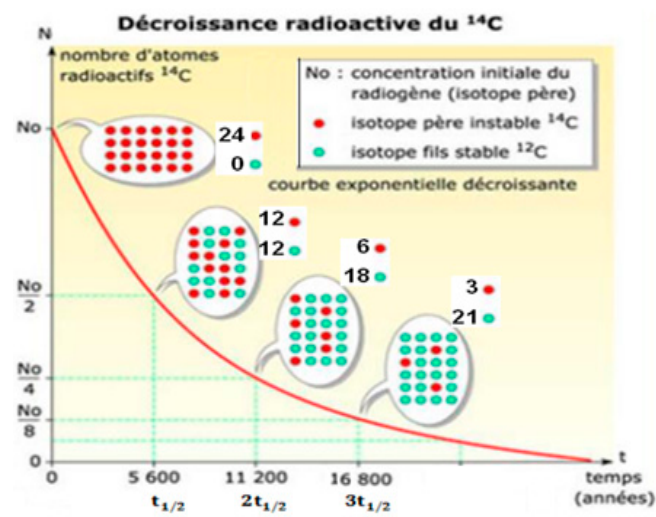

Chart 2. Graphical models of carbon $14\left({ }^{14} \mathrm{C}\right)$ radioactive decay [37].

- Expected responses

For the analytical models of radioactive decay (ModAnalyt), in the restricted case of $N\left(t=n t_{1 / 2}\right)$, the expected pupil responses are:

- From Chart 2, pupils deduce the value as $\mathrm{N}\left(\mathrm{t}=4 \mathrm{t}_{1 / 2}\right)=\frac{\mathrm{N}_{0}}{16}=\frac{\mathrm{N}_{0}}{2^{4}}$.

- From Chart 2, pupils derive the value as $\mathrm{N}\left(\mathrm{t}=5 \mathrm{t}_{1 / 2}\right)=\frac{\mathrm{N}_{0}}{32}=\frac{\mathrm{N}_{0}}{2^{5}}$.

- Results

The results are given in Table 3a below:

Table 3. (a) Test 3 (part 1) statistic results. (b) Test 3 (part 2) statistic results.

\begin{tabular}{|c|c|c|c|c|c|}
\hline \multicolumn{6}{|c|}{ (a) } \\
\hline \multirow{2}{*}{ Analysis Elements } & \multirow{2}{*}{ Branch } & \multicolumn{2}{|c|}{ Response Frequencies } & \multirow{2}{*}{$\begin{array}{l}\text { Frequency of } \\
\text { No Response }\end{array}$} & \multirow{2}{*}{ Total } \\
\hline & & Admitted & Not Admitted & & \\
\hline \multirow{6}{*}{$\begin{array}{l}\text { Deduction of the value } \\
\text { of } N(t) \text { for time } t=4 t_{1 / 2}\end{array}$} & \multirow{2}{*}{ PC } & $89.47 \%$ & $10.53 \%$ & \multirow{2}{*}{$0 \%$} & \multirow{2}{*}{$100 \%$} \\
\hline & & \multicolumn{2}{|c|}{$100 \%$} & & \\
\hline & \multirow{2}{*}{ LES } & $67.57 \%$ & $24.32 \%$ & \multirow{2}{*}{$8.11 \%$} & \multirow{2}{*}{$100 \%$} \\
\hline & & & $39 \%$ & & \\
\hline & \multirow{2}{*}{ Total } & $78.67 \%$ & $17.33 \%$ & \multirow{2}{*}{$4 \%$} & \multirow{2}{*}{$100 \%$} \\
\hline & & \multicolumn{2}{|c|}{$96 \%$} & & \\
\hline \multirow{6}{*}{$\begin{array}{l}\text { Deduction of the value } \\
\text { of } N(t) \text { for time } t=5 t_{1 / 2}\end{array}$} & \multirow{2}{*}{ PC } & $84.2 \%$ & $7.9 \%$ & \multirow{2}{*}{$7.9 \%$} & \multirow{2}{*}{$100 \%$} \\
\hline & & \multicolumn{2}{|c|}{$92.11 \%$} & & \\
\hline & \multirow{2}{*}{ LES } & $59.46 \%$ & $27.03 \%$ & \multirow{2}{*}{$13.51 \%$} & \multirow{2}{*}{$100 \%$} \\
\hline & & \multicolumn{2}{|c|}{$86.49 \%$} & & \\
\hline & \multirow{2}{*}{ Total } & $72 \%$ & $17.33 \%$ & \multirow{2}{*}{$10.67 \%$} & \multirow{2}{*}{$100 \%$} \\
\hline & & \multicolumn{2}{|c|}{$89.33 \%$} & & \\
\hline \multicolumn{6}{|c|}{ (b) } \\
\hline \multirow{2}{*}{ Analysis Elements } & \multirow{2}{*}{ Branch } & Respon & requencies & Frequency of & Tata \\
\hline & & Admitted & Not Admitted & No Response & lotal \\
\hline & PC & $68.42 \%$ & $23.68 \%$ & $700 /$ & $100 \%$ \\
\hline Fstablishment of the & $P$ & & $11 \%$ & $7.9 \%$ & $100 \%$ \\
\hline analytic expression of & I FC & $43.24 \%$ & $24.32 \%$ & 2010 & $100 \%$ \\
\hline$N(t)$ for $t=n t_{1 / 2}$ & LES & & $57 \%$ & $32.43 \%$ & $100 \%$ \\
\hline & Tot & $56 \%$ & $21.33 \%$ & 。 & O०० \\
\hline & Iotal & & $33 \%$ & $20 \%$ & $100 \%$ \\
\hline
\end{tabular}




\section{- Conclusion}

For the successful deductions of the values of $\mathrm{N}\left(4 \mathrm{t}_{1 / 2}\right)$ and $\mathrm{N}\left(5 \mathrm{t}_{1 / 2}\right)$ in Table $3 a$, they are at the observed average of $92.66 \%(92.66 \%=(72+67) /(75+75))$, all branches combined. But, the answers allowed an average turnaround of $75.33 \%(75.33 \%=(59+54) /(75+75))$. The recurring remark we can make again is that the performances of the pupils of the PC branch exceed those of the pupils of the LES branch.

We can conclude that a good part of the pupils is on the way to apprehension of the evolution of the radioactive population at the end of the passage of each time interval of value $t_{1 / 2}$. So, the intelligibility frame of test 3 devolution allowed pupils to design a mental model. For them to continue the process of this mathematical modeling, on the way to the construction of a general mathematical model, we link to the second part of the test 3 . Henceforth, blockages are a thing of the past.

\subsubsection{Test 3 (Part 2)}

- Statement

Using the information in Chart 2 and the previous test, deduce an analytical model of $N(t)$ for times $\mathrm{t}=\mathrm{nt}_{1 / 2}$, where $\mathrm{n}$ is a new parameter that we call "the radioactive decay order". $\mathrm{n}$ is a natural number (n€IN) (sixth sequence).

- Expected responses

For the analytical models of radioactive decay (ModAnalyt), in the restricted case of $N\left(t=n t_{1 / 2}\right)$, the expected pupil outputs are:

- From Chart 2 and the results of the test 1 (part 1), pupils deduce the expression of the population number as $\mathrm{N}\left(\mathrm{t}=\mathrm{nt}_{1 / 2}\right)=\frac{\mathrm{N}_{0}}{2^{\mathrm{n}}}$, for $\mathrm{n}$ any natural integer.

- $\quad$ Results

The results are given in Table $3 \mathrm{~b}$ below:

\section{- Conclusion}

In the particular case where $\mathrm{t}=\mathrm{nt}_{1 / 2}$, the total of $56 \%$ as the frequency of the accepted responses is significant (Table $3 b)$. In fact, the success that the pupils generated for the analytical model of $N\left(n_{1 / 2}\right)$ jumped from $0 \%$ under the model of the official instructions, to $68.42 \%$ and $43.24 \%$, respectively, for the pupils of the PC and LES branches. In fact, of the correct respondents, almost $60 \%$ are from the PC branch, compared to $40 \%$ from the LES branch. We can conclude, therefore, that the results of the preliminary study and those of the validation study are compatible. However, we interpret the non-mastery of mathematics, by its translation among LES branch pupils by more abstention $(32.43 \%$ of no answers), so that it is translated among PC branch pupils by more productions out of mathematical frame (23.68\% of non-accepted answers).

So, in the test 3 account, we can conclude that in the paradigm of the case study, the internal comparison conducted separately on a class of the second year of the baccalaureate of the LES branch and on another of the PC branch, allowed us to identify the good performances of the pupils in the apprehension and the fulfillment of the process of the mathematical modeling of the radioactive decay. It is, actually, thanks to their devolutions in the registers and frames related to contents that they frequently use, expected by all the partners of the class.

\subsubsection{Pre-Test 4}

\section{- Statement}

We performed a discretization at time intervals equal to the half-life $t_{1 / 2}$. We were able to approach the real curve in black (ModLet), (ModLet: Model of the radioactive decay Law in exponential of time. 
While ModLI is the Model of the same law obtained by Linearization per Interval of its corresponding curve.) by a succession of functions affine in red, as the following Chart 3 shows (seventh sequence).

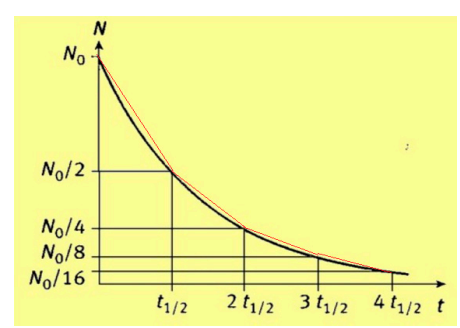

Chart 3. ModLe ${ }^{t}$ curve in black and ModLI curve in red.

We successively give you the curves and the expressions of these functions, for the first three orders of radioactive decay.

Follow the instructions hereafter (eighth sequence):

Curve of ModLI up to $\mathrm{n}=1$ :

For Chart 4: $\mathrm{n}=1$, so $\left.\mathrm{t} \in] 0, \mathrm{t}_{1 / 2}\right]$ and

$$
\mathrm{N}(\mathrm{t})=\frac{\mathrm{N}_{0}}{2^{1}}\left[(1+1)-\frac{\mathrm{t}}{\mathrm{t}_{1 / 2}}\right]
$$

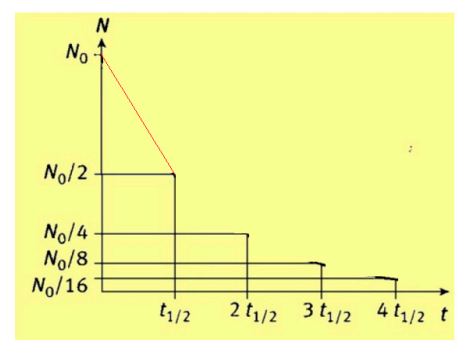

Chart 4. ModLI curve up to $n=1$.

Establish the expression of $\mathrm{t}$ for $\mathrm{n}=1$.

Curve of ModLI up to $\mathrm{n}=2$ :

For Chart 5: $n=2$, so $\left.t \in] t_{1 / 2}, 2 t_{1 / 2}\right]$ and

$$
\mathrm{N}(\mathrm{t})=\frac{\mathrm{N}_{0}}{2^{2}}\left[(2+1)-\frac{\mathrm{t}}{\mathrm{t}_{1 / 2}}\right]
$$

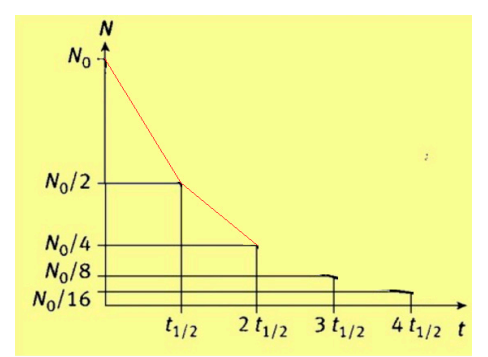

Chart 5. ModLI curve up to $n=2$.

Establish the expression of $\mathrm{t}$ for $\mathrm{n}=2$.

Curve of ModLI up to $n=3$ : 
For Chart 6: $\mathrm{n}=3$, so $\left.\mathrm{t} \in] 2 \mathrm{t}_{1 / 2}, 3 \mathrm{t}_{1 / 2}\right]$ and

$$
\mathrm{N}(\mathrm{t})=\frac{\mathrm{N}_{0}}{2^{3}}\left[(3+1)-\frac{\mathrm{t}}{\mathrm{t}_{1 / 2}}\right]
$$

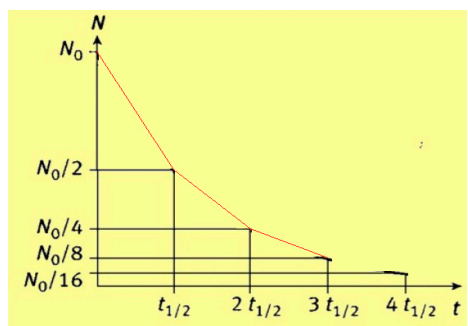

Chart 6. ModLI curve up to $\mathrm{n}=3$.

Establish the expression of $\mathrm{t}$ for $\mathrm{n}=3$.

- Curve of ModLI up to $n=4$ :

Add the necessary information to the text with holes below (ninth sequence).

For Chart 7, the natural integer is $\mathrm{n}=4$, then $\mathrm{t} \in \ldots \ldots \ldots$. and $\mathrm{N}(\mathrm{t})=$ while $\mathrm{t}=$ In general, for any order of radioactive decay $n$, the corresponding time interval is written by $t \in$............., on which the expression of the number $\mathrm{N}(\mathrm{t})$ of radioelement is $\mathrm{N}(\mathrm{t})=\ldots \ldots \ldots$, and that of time $\mathrm{t}$ is $\mathrm{t}=$

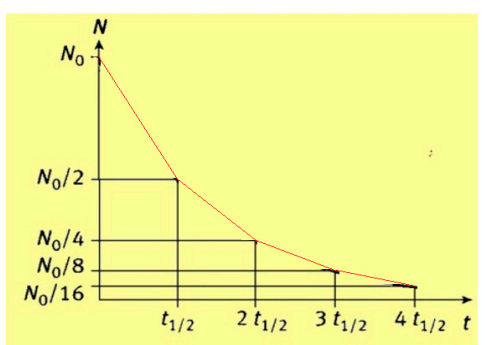

Chart 7. ModLI curve up to $n=4$.

- $\quad$ Expected responses

About the analytical models of radioactive decay named ModLI, the expected pupil outputs are: For the general expression of the population number:

$$
\left.\left.\mathrm{N}(\mathrm{t})=\frac{\mathrm{N}_{0}}{2^{\mathrm{n}}}\left[(\mathrm{n}+1)-\frac{\mathrm{t}}{\mathrm{t}_{1 / 2}}\right] \text { with } \mathrm{t} \in\right](\mathrm{n}-1) \mathrm{t}_{1 / 2}, \mathrm{nt}_{1 / 2}\right] .
$$

For the general expression of the time:

$$
\mathrm{t}=\mathrm{t}_{1 / 2}\left[(\mathrm{n}+1)-2^{\mathrm{n}} \frac{\mathrm{N}(\mathrm{t})}{\mathrm{N}_{0}}\right] \text { with }
$$

- $\quad$ Results

The results are given in Table 4 below: 
Table 4. Pre-test 4 results.

\begin{tabular}{|c|c|c|c|c|c|}
\hline \multirow{2}{*}{ Analysis Elements } & \multirow{2}{*}{ Branch } & \multicolumn{2}{|c|}{ Responses Frequency } & \multirow{2}{*}{$\begin{array}{l}\text { Frequency of No } \\
\text { Responses }\end{array}$} & \multirow{2}{*}{ Total } \\
\hline & & Admitted & No admitted & & \\
\hline \multirow{6}{*}{$\begin{array}{l}\text { establishment of the } \\
\text { expression of time } t \text { for } n=1\end{array}$} & \multirow{2}{*}{ PC } & $36.84 \%$ & $60.53 \%$ & \multirow{2}{*}{$2.63 \%$} & \multirow{2}{*}{$100 \%$} \\
\hline & & \multicolumn{2}{|c|}{$97.37 \%$} & & \\
\hline & \multirow{2}{*}{ SVT } & $5.41 \%$ & $94.59 \%$ & \multirow{2}{*}{$0 \%$} & \multirow{2}{*}{$100 \%$} \\
\hline & & & $\%$ & & \\
\hline & \multirow{2}{*}{ Total } & $21.33 \%$ & $77.33 \%$ & \multirow{2}{*}{$1.33 \%$} & \multirow{2}{*}{$100 \%$} \\
\hline & & \multicolumn{2}{|c|}{$98.67 \%$} & & \\
\hline \multirow{6}{*}{$\begin{array}{l}\text { establishment of the } \\
\text { expression of time } t \text { for } n=2\end{array}$} & \multirow{2}{*}{ PC } & $44.74 \%$ & $50 \%$ & \multirow{2}{*}{$5.26 \%$} & \multirow{2}{*}{$100 \%$} \\
\hline & & \multicolumn{2}{|c|}{$94.74 \%$} & & \\
\hline & \multirow{2}{*}{ LES } & $5.41 \%$ & $81.08 \%$ & \multirow{2}{*}{$13.51 \%$} & \multirow{2}{*}{$100 \%$} \\
\hline & & & $9 \%$ & & \\
\hline & \multirow{2}{*}{ Total } & $25.33 \%$ & $65.33 \%$ & \multirow{2}{*}{$9.33 \%$} & \multirow{2}{*}{$100 \%$} \\
\hline & & & $7 \%$ & & \\
\hline \multirow{6}{*}{$\begin{array}{l}\text { establishment of the } \\
\text { expression of time } t \text { for } n=3\end{array}$} & \multirow{2}{*}{ PC } & $73.68 \%$ & $26.32 \%$ & $0 \%$ & $100 \%$ \\
\hline & & & $\%$ & $0 \%$ & $100 \%$ \\
\hline & I ES & $40.54 \%$ & $54.05 \%$ & $541^{\circ}$ & $100 \%$ \\
\hline & LES & & $5 \%$ & $0.41 \%$ & $100 \%$ \\
\hline & $T$ & $57.33 \%$ & $40 \%$ & & \\
\hline & Iotal & & $33 \%$ & $2.0 \% \%$ & $100 \%$ \\
\hline & $\mathrm{PC}$ & $71.05 \%$ & $18.42 \%$ & $1062 \%$ & $100 \%$ \\
\hline & & & $17 \%$ & & \\
\hline $\begin{array}{l}\text { deduction of the expression } \\
\text { for } N(t) \text { and } t \text { if } n=4\end{array}$ & IFS & $67.57 \%$ & $29.73 \%$ & $27 \%$ & $100 \%$ \\
\hline & LES & & $3 \%$ & $2.1 \%$ & $100 \%$ \\
\hline & Tat & $69.33 \%$ & $24 \%$ & $470 /$ & $1000 /$ \\
\hline & Tolat & & $33 \%$ & $0.0 \% \%$ & $100 \%$ \\
\hline & R & $73.68 \%$ & $26.32 \%$ & Qo/ & 1000 \\
\hline & & & $0 \%$ & & \\
\hline deduction of the general & 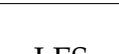 & $56.76 \%$ & $43.24 \%$ & $00 \%$ & 1000 \\
\hline & LES & & $\%$ & $0 \%$ & $100 \%$ \\
\hline & Totol & $65.33 \%$ & $34.67 \%$ & $0 \%$ & $100 \%$ \\
\hline & Iotal & & $\%$ & $0 \%$ & $100 \%$ \\
\hline
\end{tabular}

\section{- $\quad$ Results}

The null or negligible frequency of the copies containing no answers, all branches combined (Table 4), shows that the context is intelligible to them. Indeed, these pupils no longer feel stuck in the execution of modeling activities, even though $34.67 \%$ of them did not answer. In addition, the success of the $65.33 \%$ of pupils in the development of the general expression of the ModLI confirms that the teaching-learning of modeling, in physics, is recommendable in the mathematical frames and registers of the usual treatments [38]. 


\subsubsection{Post-test 4}

- Statement

We want to prepare a radioactive sample of polonium $210\left({ }^{210} \mathrm{Po}\right)$, radioactive activity $a_{0}=5 \mathrm{~Bq}$, at the time of its preparation.

Calculate $\mathrm{a}(\mathrm{t})$ the radioactive activity for $\mathrm{t}=30$ days after this preparation.

We give: $\mathrm{n}=1$, and for ${ }^{210} \mathrm{Po}$ is $\mathrm{t}_{1 / 2}=138 \mathrm{j}$ (10th sequence).

Note: The data from the exercise above is found, exactly, both on the "MASSAR" textbooks for the LES pupils, and "FADAE" for the PC pupils. To adapt the exercise to the context of ModLI, only one datum was added to the last line. It provides information on the new parameter that we call radioactive decay order.

- $\quad$ Results

The results are given in Table 5 below:

Table 5. Post-test 4 results.

\begin{tabular}{|c|c|c|c|c|c|c|}
\hline \multirow[b]{2}{*}{ Branch } & \multirow[t]{2}{*}{$\begin{array}{l}\text { Analysis } \\
\text { Elements }\end{array}$} & \multicolumn{2}{|c|}{$\begin{array}{l}\text { Frequency of Unlocking } \\
\text { Situations by ModLI }\end{array}$} & \multicolumn{2}{|c|}{ Frequency of Blocking Situations } & \multirow{2}{*}{ Total } \\
\hline & & $\begin{array}{l}\text { Successful } \\
\text { Use }\end{array}$ & $\begin{array}{l}\text { Unsuccessful } \\
\text { Use }\end{array}$ & $\begin{array}{l}\text { Use of } \\
\text { ModLe }\end{array}$ & $\begin{array}{l}\text { No Response or } \\
\text { Others }\end{array}$ & \\
\hline \multirow{2}{*}{\multicolumn{2}{|c|}{ PC }} & $73.68 \%$ & $13.16 \%$ & $5.26 \%$ & $7.89 \%$ & \multirow{2}{*}{$100 \%$} \\
\hline & & \multicolumn{2}{|c|}{$86.84 \%$} & \multicolumn{2}{|c|}{$13.16 \%$} & \\
\hline \multirow{2}{*}{\multicolumn{2}{|c|}{ LES }} & $72.97 \%$ & $10.81 \%$ & $8.11 \%$ & $8.11 \%$ & \multirow{2}{*}{$100 \%$} \\
\hline & & \multicolumn{2}{|c|}{$83.78 \%$} & \multicolumn{2}{|c|}{$16.22 \%$} & \\
\hline \multirow{2}{*}{\multicolumn{2}{|c|}{ Total }} & $73.33 \%$ & $12 \%$ & $6.67 \%$ & $8 \%$ & \multirow{2}{*}{$100 \%$} \\
\hline & & \multicolumn{2}{|c|}{$85.33 \%$} & \multicolumn{2}{|c|}{$14.67 \%$} & \\
\hline
\end{tabular}

\section{- Conclusion}

Although the duration of the validation study was relatively short, it was enough for $73.33 \%$ of pupils to apply ModLI appropriately (Table 5). This model now offers an adequate intelligibility frame. However, compared to the results of the pre-test 4 , there are $26.67 \%$ of pupils who have very large residual weaknesses in mathematics. They still face serious difficulties in understanding the process of developing a mathematical model in physics.

\section{Conclusions}

For ModLI, the preliminary study and the validation study that we conducted allowed us to test it as a model of radioactive decay. This model mobilizes semiotic and semantic registers in the physical and mathematical frames related to contents frequently used by pupils. However, with ModLe ${ }^{t}$, pupils are completely inactive once when they reach the mathematical phase of the introduction of analytical models of radioactive decay.

We can conclude that under ModLI, the teaching-learning of the phenomenon of radioactive decay has considerably improved by combining it doubly, with collaborative work between pupils and with the mobilization of ICT resources. The results of our studies revealed that the pupils were very satisfied. Indeed, all branches combined, the frequency of their copies containing no response was null or very negligible. Again, the preliminary study shows an increase of $65.33 \%$ in the expected completion of the mathematical modeling process leading to the development of the general expression of ModLI. Moreover, the validation study shows that under ModLI, pupils show a 75\% increase in success in carrying out activities related to the application of their learning on the radioactive decay law. 
Supplementary Materials: The following are available online at http://www.mdpi.com/2227-7102/9/2/123/s1.

Author Contributions: Conceptualization, A.M.; Formal analysis, A.M; Investigation, A.M; Methodology, A.M; Resources, A.M; Software, A.M; Supervision, N.B.; Validation, N.B.

Funding: The authors declare no external funding.

Conflicts of Interest: The authors declare no conflict of interest.

\section{References}

1. Lévy-Leblond, J.-M. Physique et Mathématique, Encyclopædia Universalis, Consulté le 12 août. 2014. Available online: http://www.universalis.fr/encyclopedie/physique-physique-et-mathematique/ (accessed on 12 August 2014).

2. Kuhn, T.S. Tradition mathématique et tradition expérimentale dans le développement de la physique. Ann. Hist. Sci. Soc. 1975, 30, 975-998.

3. Kastler, M.A. Ampère et les lois de l'électrodynamique. Rev. Hist. Sci. Paris 1977, 2, 143-157. [CrossRef]

4. Bensaude Vincent, B. Paul Paul Langevin: L'histoire des sciences comme remède à tout dogmatisme/Paul Langevin: History of science as a remedy for every dogmatism Langevin: L'histoire des sciences comme remède à tout dogmatisme/Paul Langevin: History of science as a remedy for every dogmatism. Rev. Hist. Sci. Paris 2005, 58, 311-328.

5. Rosmorduc, J. L'histoire de la physique peut-elle eclairer les obstacles epistemologiques? Aster 1987, 5, 117-142. [CrossRef]

6. Mayrargue, A.; Savaton, P. Quels liens entre l'histoire des sciences, l'épistémologie et la didactique des disciplines? Tréma 2006, 26. [CrossRef]

7. Martinand, J. Histoire et didactique de la physique et de la chimie: Quelles relations? Didaskalia 1993, 2, 89-99. [CrossRef]

8. Duval, R. Quel cognitif retenir en didactique des mathématiques. Rech. Didact. Math. 1996, 16, 349-382.

9. Malafosse, D.; Lerouge, A.; Dusseau, J. Étude en inter-didactíque des mathématiques et de la physique de 1' acquisition de la loi d' Ohm au collège: Espace de réalité. Didaskalia 2000, 16, 81-106.

10. Mastafi, M. Intégration et usages des TIC dans le système éducatif marocain: Attitudes des enseignants de l'enseignement primaire et secondaire. Adjectif. Net Mis en ligne dimanche 28 avril 2013 [En ligne]. Available online: http://www.adjectif.net/spip/spip.php?article228 (accessed on 1 June 2019).

11. Mamane, A.; Benjelloun, N. Study of the Dependence between the Teaching- Learning of Physics and the ICT Resources available to Pupils in Moroccan High Schools. IJEIS Int. J. Educ. Inf. Stud. 2018, 8, 1-15.

12. Conseil Supérieur de l'Éducation de la Formation et de la Recherche Instance Nationale d'Evaluation du Système d'Education de Formation et de la Recherche Scientifique. Royaume du Maroc Résultats des Elèves Marocains en Mathématiques et en Sciences dans un Contexte International; TIMSS 2015. Available online: http://www.csefrs.ma/wp-content/uploads/2018/06/TIMSS-Version-Fr-26-05-2018.pdf (accessed on 1 June 2019).

13. Mamane, A.; Benjelloun, N. Mathematical modeling, ICT and collaborative work in Moroccan high schools: From ModLet to ModL2t, experimentation of a semiotic set in the teaching and learning of the radioactive decay law. In Proceedings of the Apel'2018 FST Fès: 3ème édition de la Conférence International sur les Approches Pédagogique et E-Learning, FST Fez, Morocco, 26-27 December 2018.

14. Klein, L.; Kagan, D. “ Radio-Active " Learning: Visual Representation of Radioactive Decay Using Dice. Phys. Teach. 2010, 45, 5-6. [CrossRef]

15. Jesse, K.E. Computer Simulation of Radioactive Decay. Phys. Teach. 2003, 542, 9-11. [CrossRef]

16. Schultz, E. Dice-Shaking as an Analogy for Radioactive Decay and First-Order Kinetics. J. Chem. Educ. 1997, 74, 505-507. [CrossRef]

17. Bakaç, M.; TaúR-lu, A.K.; Uyumaz, G. Modeling radioactive decay. Procedia-Soc. Behav. Sci. 2011, 15, 2196-2200. 
18. Edge, R.D. Radioactive Decay-An Analogy. Phys. Teach. 1978, 445-458. Available online: https://aapt. scitation.org/doi/10.1119/1.2340024 (accessed on 1 June 2019). [CrossRef]

19. Hughes, E.A.; Zalts, A. Radioactivity in the Classroom. J. Chem. Educ. 2000, 77, 6-7. [CrossRef]

20. Lapp, D.R. Obtaining and Investigating Unconventional Sources of Radioactivity. Phys. Teach. 2010, 90, 10-13. [CrossRef]

21. Direction des programmes Ministère de l'éducation nationale et de l'enseignement supérieur et de la formation des cadres et de la recherche scientifique Royaume du Maroc. Instructions Pédagogiques et Programmes Spécifiques de L'enseignement de la Physique et de la Chimie au Cycle Secondaire Qualifiant. 2007. Available online: https://waliye.men.gov.ma/Ar/curriculum1/Documents/curr_progr\%20Physique\%20et $\%$ 20Chimie.pdf (accessed on 1 June 2019).

22. Direction des programmes Ministère de l'éducation nationale et de l'enseignement supérieur et de la formation des cadres et de la recherche scientifique Royaume du Maroc. Instructions Pédagogiques et Programmes Spécifiques de L'enseignement des Mathématiques au Cycle Secondaire Qualifiant. 2017. Available online: https://waliye.men.gov.ma/Ar/curriculum1/Documents/curr_progr\%20Math\%C3\%A9matiques.pdf (accessed on 1 June 2019).

23. Mamane, A.; Benjelloun, N. Mathematical modeling, ICT and collaborative work in Moroccan high schools: From ModLet to ModL2t, experimentation of a semiotic set in the teaching and learning of the radioactive decay law. IOSR J. Res. Method Educ. 2018, 8, 32-40.

24. Artigue, M. Ingéniérie didactique. Vème École D'été Didact; Mathématiques Rennes; Des Mathématiques L'informatique Publ. L'institut Rech: Rennes, France, 1989; pp. 124-128.

25. Duval, R. Registres de représentation sémiotique et fonctionnement cognitif de la pensée. Ann. Didact. Sci. Cogn. 1993, 5, 37-65.

26. Malafosse, D.; Lerouge, A.; Dusseau, J. Étude en inter-didactíque des mathématiques et de la physique de l'acquisition de la loi d'Ohm au collège: Changement de cadre de rationalité. Didaskalia 2001, 18, 61-98. [CrossRef]

27. Malafosse, D. Pour une formation inter-didactique Mathématiques-Physique des professeurs de collège et de lycée. Tréma 2003, 20-21, 187-209. [CrossRef]

28. Malonga Moungabio, F.; Beaufils, D. Modélisation et registres sémiotiques: Exemple d'étude de manuels de physique de terminale. RDST 2010, 1, 293-316. [CrossRef]

29. Martinand, J. Introduction à La Modélisation; INRP: Paris, France, 1987; Available online: http://www.inrp.fr/ Tecne/Rencontre/Univete/Tic/Pdf/Modelisa.pdf (accessed on 1 June 2019).

30. Douady, R. Ingénierie didactique et évolution du rapport au savoir. Repères IREM 1994, 15, 37-61.

31. Marty, O. Cours Ingénierie Didactique; 2015 Université de Lille 1. 2015. Available online: https://halshs. archives-ouvertes.fr/cel-01260590/document (accessed on 1 June 2019).

32. Droui, M. L'impact d'une Simulation sur des Dispositifs Mobiles et en Situation de Collaboration sur la Comprehension de L'effet Photoelectrique au Niveau Collegial; Université de Montréal: Montreal, QC, Canada, 2012; Volume NR98438.

33. Charuau, J.; Labed, V.; Robe1, M.C.; Venin, J.C.; Aubert, C.; Fazileabasse, J.; Florence, D.; Gibaud, C.; Heleschewitz, H.; Klein, D.; et al. Manifestation la radioactivité du Radon 222 dans la nature. Radioprotection 1996, 31, 371-388. [CrossRef]

34. Mermoz, L.J.; Louis, S.; Rhin, H. France Radioactivité et réactions nucléaires-TP activité du granite. Available online: http://physicus.free.fr/premiere_S/1S-CHAP-08-radioact-reac-nuc.php (accessed on 1 June 2019).

35. CCNR. EDP-Sciences Famille radioactive de l'uranium 238., Canadian Coalition for Nuclear Responsibility, 53 Dufferin Road, Hampstead QC. Available online: http://www.ccnr.org/decay_U238_f.html (accessed on 1 June 2019).

36. Ministère de l'éducation nationale et de la jeunesse. France Baccalauréat des Voies Générale et Technologique Épreuve de Physique-Chimie de Série S Physique, Enseignement Obligatoire: Décroissance Radioactive du Radon 220 Décroissance Radioactive Du Radon 220; Ministry of National Education, 2002; p. 7. 
37. Asp, A. Scolaire Personnalisée La décroissance Radioactive du Carbone 14. Available online: https://www.assistancescolaire.com/enseignant/elementaire/ressources/base-documentaire-ensciences/la-decroissance-radioactive-du-carbone-14-t_t103i03 (accessed on 1 June 2019).

38. Mamane, A.; Benjelloun, N. Modélisations mathématiques, TICE et travail collaboratif dans l'enseignement-apprentissage de la décroissance radioactive aux lycées du Maroc par le Modèle de Linéarisation par Intervalle ModLI". In Proceedings of the Workshop LIRDIST Université Sidi Mohamed Ben Abdellah Fés, 6-7 July 2018.

(C) 2019 by the authors. Licensee MDPI, Basel, Switzerland. This article is an open access article distributed under the terms and conditions of the Creative Commons Attribution (CC BY) license (http://creativecommons.org/licenses/by/4.0/). 